\title{
An Assessment of Measures Medical Imaging Personnel Use to Avoid the Breakdown of Diagnostic Radiologic Equipment in Some Health Facilities in Northwest and Southwest Regions of Cameroon
}

\author{
Awo Macclevis Daki, Ndzi Sandry Mugop, Fondzenyuy Claudia Berinyuy and Soweh Raymond Mbinkong.
}

\begin{abstract}
The proper and correct diagnosis of diseases is the primary necessity before the treatment and so sophisticated equipment are needed for better diagnosis. Frequent breakdown of these equipment faced by personnel during service delivery lead to movement of patients to other health facilities, failure to attend to patients for which in case of emergency will lead to death of patients. This was an investigative cross sectional study aimed at assessing measures to avoid equipment breakdown. This study was carried out in some selected health facilities in the North West and South West regions of Cameroon which lasted for 1 month (from the $22^{\text {nd }}$ January to $21^{\text {st }}$ February 2019). Semi-structured questionnaires were designed and used to collect primary data from 20participants in the sampled hospitals. Data collected was analyzed using SPSS (statistical package for social sciences) version 23.0 by the research analyst. The results obtained showed thatout of the 20 participants, $(15) 75 \%$ were males while(5)25\% were females. The most represented age group was the 20-30 years age group, and the least represented age group was in the 42-52. The most common cause of equipment breakdown was electrical faults $(75 \%), 45 \%$ of participantsdid not carry out quality control programs and the measures to avoid this breakdown was the use of appropriate parameters $(80 \%)$.Based on results obtained, it was concluded that the major cause of equipment breakdown was electrical faults.
\end{abstract}

\section{INTRODUCTION}

\section{$>$ Background}

The rapid progress of medical science and the invention of diagnostic radiological equipment in medicine have benefited mankind and the whole civilization. The proper and correct diagnosis of diseases is the primary necessity before the treatment and so the more sophisticated the bio-instruments are, better diagnosis will be possible (Debashiset al, 2010). They provide fast and accurate diagnosis, resulting in the improvement of health outcomes and the quality of life for the patient (Boris et al, 2014). Medical imaging refers to the techniques and processes used to create images of the human body for various clinical purposes such as medical procedures and diagnosis or medical science including the study of normal anatomy and function (Debashiset al, 2010). Medical imaging comprises of several techniques which could be diagnostic or therapeutic but here we will be talking on diagnostic techniques some of which are radiography, ultrasonography, mammography, computed tomography etc. Diagnostic imaging is critical for management of patients and diagnosis of disease throughout the world. These tests rely on a wide variety of equipment used to visualize the human body and identify diseases (Monika, 2018). Radiology Equipment is the major tool of any radiology department. The quest for improved health care services led to an increasing need for production of radiology equipment that strikes a balance between production of high quality diagnostic images and reduced radiation dose to patients. Modern radiological equipment has a great reduction in equipment size in many cases, improve diagnostic imaging efficiency and speed, it however necessitates higher maintenance and quality control requirements than was required for the older models. (Okejiet al, 2012).

The availability and use of medical imaging equipment is undoubtedly on the increase which means wear and tear is expected by users (Ekpo et al, 2013). While health technology has shown constant improvements in industrialized countries, developing countries have not been able to take full advantage of this evolution, partly because of unstable power supplies. According to a WHO study, grid failures are responsible for one-third of medical device breakdowns (Merlin et al, 2015). Regarding power supply in particular; regular blackouts cause frequent unavailability of medical devices and health services, while many devices are even damaged by electrical surges and transients. The most common single cause of failure in developing countries is the power supply (29.9\%). (Merlin et al, 2015).

The broad legal requirements for quality control (QC) of medical imaging equipment exist in most developed countries. Developing countries have yet to fully establish adequate guidelines to match those in developed countries, especially for X-ray equipment performance and image quality criteria (Korir et al, 2013). Quality control is an ongoing process of evaluation of medical imaging equipment (Delis et al, 2017). Studies have shown that there was Little presence of quality control programs $(15 \%)$ and complete absence of planned preventive maintenance in the hospitals which may have accounted for the frequent breakdown, large numbers of unserviceable equipment and long down time when faults developed (mark et al, 2012). 
Research have shown that in hospitals in developing countries in Africa only few implement quality control measures and their equipment function normally, majority of hospitals have equipment breakdown for which very few are maintained immediately or within few days after failure. Majority are maintained after sometime. (Ekpoet al, 2013).

\section{$>\quad$ Statement of the Problem}

Diagnostic medical imaging equipment is aimed at diagnosing pathologies and abnormalities of the human body. Frequent breakdown of these equipment faced by technologist during service delivery leads to movement of patients to other health facilities, failure to attend to patients and patients might wait for long for maintenance to be done for whichin cases of emergency will lead to death. Therefore thisstudy was aimed at evaluating the measures medical imaging personnel use to avoid the breakdown of the equipment.

\section{$>$ Significance of the Study.}

- This study will help the imaging staff to understand the importance of quality controlprograms which will help to maintain the life span of diagnostic radiological equipment.

- Statistical values from this research work will be use during lectures and seminars to educate technologist.

- This study will educate the personnel on some of the causes of breakdown of their equipment.

\section{$>$ Research Questions}

- What are the causes of equipment breakdown?

- How often is quality control being done?

- What are the measures use to avoid the breakdown of the equipment?

\section{$>$ Research Objectives}

\section{- Main Objective}

The purpose of this study was to assess the measures imaging personnel are using to avoid the breakdown of equipment.

- Specific objectives

$\checkmark$ Causes of breakdown of the equipment

$\checkmark$ To determine how often quality control is being carried out.

$\checkmark \quad$ To evaluate measures taken by personnel to avoid breakdown of the equipment

\section{$>$ Research Scope and Delimitation}

The scope of this study was to assess the measures to avoid the breakdown of diagnostic imaging equipmentand it is as complex as they exist a wide range of methods. However the scope of this work limits to the general assessment of practices imaging personnel would use to avoid the breakdown of some diagnostic imagingequipment.

\section{$>$ Definitions of Terms and Concepts}

\section{- Medical imaging}

Medical imaging encompasses different imaging modalities and processes to image the human body for diagnostic and treatment purposes and therefore plays an important role in initiatives to improve public health for all population groups.(WHO, 2019)

\section{- Radiologic equipment}

It is any medical radiation device that emits ionizing or non-ionizing radiation or detects the radiation for the purpose of Diagnosing disease or other medical condition in humans, or treating, curing, mitigating, or preventing disease in humans. (Utah code, 2011)

\section{- Imaging personnel}

They are health care professionals with appropriate training, skills and experiences to perform a wide range of radiologic procedures under the supervision of the physician. They also carry out quality control measures of the equipment. (AAFP, 2019)

\section{MATERIALS AND METHODS}

\section{$>$ Study Design:}

This was an investigative cross sectional study which started on the $22^{\text {nd }}$ of January to $21^{\text {st }}$ of February 2019.

\section{Study Setting:}

A hospital based study which was done in Bamenda, Limbe and Buea subdivision of the North West and South West regions of Cameroon. The randomly selected health unit in the various health areas of Bamenda Health District being; Regional Hospital Bamenda, Providence Polyclinic,Ring land medical center, Mezam Polyclinic and St Blaise. They were informed by application through their administrators attached with the school clearance and authorization letter from the North West regional delegation of public health.The randomly selected health units in the various health areas of the south west health district being; Regional hospital Limbe, Regional Hospital Buea, and District hospitalBotaLimbe were informed by application through their administrators with the use of school clearance.

\section{Study Population}

This study included all the radiology technologists and sonographers working in the selected health unit at the health areas of the North West and South West Health District.

- Inclusion Criteria:

$\checkmark$ All radiology technologists/technicians working in the selected health units.

$\checkmark$ Sonographers working in the selected health unit. 
- Exclusion Criteria:

$\checkmark$ All patients and their care takers for radiological diagnosis.

$\checkmark \quad$ Secretaries in the imaging unit.

$\checkmark \quad$ Internship students.

\section{$>$ Sampling:}

The probability sampling method of simple random sampling and the non-probability sampling method of convenience sampling were used during this study.

\section{- Sample Size calculation:}

The Sample size was calculated using Cochran's formula, based on a study carried out by (merlin et al, 2015) In which the most common single cause of equipment failure was due to power supply in Cameroon $(\mathrm{p}=0.299)$

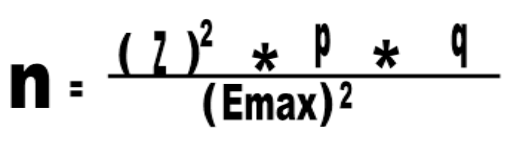

Confidential level $=95 \%$

\section{$\mathrm{Z}=\mathbf{1 . 9 6}$}

Emax $=0.05$

$p=0.299$

$q=1-p(0.701)$

Giving a sample size of 322, for duration of 10 months which the study was done, working now for 1 month our minimum sample size was 26 .

\section{- $\quad$ Sampling Method:}

Participants were selected through a convenient random sampling method.

\section{Data collection procedures}

The variables to be measured are the cause of breakdown, measures taken to avoid breakdown and the quality control in the unit.
> Data Collection Tools:

- Data was obtained by giving out semi-structured questionnaires design purposely for this study to the participants.

- A phone camera (Techno canon) was used to capture equipment images of interest

- A pen and a book was used to write down some observation

\section{$>$ Data Management and Analysis:}

The collected data was tallied, edited and saved in Microsoft excel 2013 spreadsheet and later stored in the computer.The stored data was analyzed using SPSS (statistical package for social sciences) version 23.0 by the research analyst.

\section{$>$ Ethical Considerations \\ - Ethical approval}

An authorization for carrying out this study was obtained from the school administration of St Louis University Institute of Health and Biomedical sciences, after reading and adopting the research proposal and an administrative authorization for carrying out the study was obtained from the Northwest Regional Delegation of Public Health, with authorization from the various hospital enrolled for the study.

- Confidentiality

$\checkmark$ The participant's privacy and confidentiality was respected.

$\checkmark \quad$ Participants were assured that all information collected was used only for the purpose of the study.

$>$ Limitations of the Study:

- There was 2 weeks lockdown in the 2 regions during the study.

- Inability of newly recruited personnel to answer the questionnaires.

- Delayed to get authorisation from the studied hospitals.

\section{RESULTS}

\begin{tabular}{|c|c|}
\hline Characteristics & No. Examined (\%) \\
\hline $\begin{array}{c}\text { Gender: Male } \\
\text { Female }\end{array}$ & $\begin{array}{c}15(75 \%) \\
5(25 \%)\end{array}$ \\
\hline $\begin{array}{c}\text { Age group (years): } 20-30 \\
31-41 \\
42-52 \\
53-63\end{array}$ & $\begin{array}{c}10(50 \%) \\
9(45 \%) \\
1(5 \%) \\
0\end{array}$ \\
\hline $\begin{array}{c}\text { Level of Education: HND/HPD } \\
\text { DEGREE } \\
\text { MASTERS } \\
\text { PHD }\end{array}$ & $\begin{array}{c}5(25 \%) \\
13(65 \%) \\
2(10 \%) \\
0\end{array}$ \\
\hline $\begin{array}{c}\text { Work Experience: } \\
6-10 \mathrm{yrs} \\
11-15 \mathrm{yr} \\
>15 \mathrm{yrs}\end{array}$ & $\begin{array}{c}\mathbf{1 0}(\mathbf{5 0} \%) \\
8(40 \%) \\
1(5 \%) \\
1(5 \%)\end{array}$ \\
\hline Total & $20(100 \%)$ \\
\hline
\end{tabular}

Table 1:- Demographic Distribution of the Study Population 
Out of the 20 participants in the sampled hospitals, $15(75 \%)$ were males and the $5(25 \%)$ were females. The most represented age group was the 20-30yrs (50\%) and the least represented age group was the 42-52 (5\%). Majority of the participants had bachelor's degree (65\%) and few had master's degree (10\%). Majority of the participants (50\%) had work experience 1-5yrs and the least $(5 \%)$ had work experience 11-15 and >15yrs

\section{Causes of Breakdown of Diagnostic Radiological Equipment}

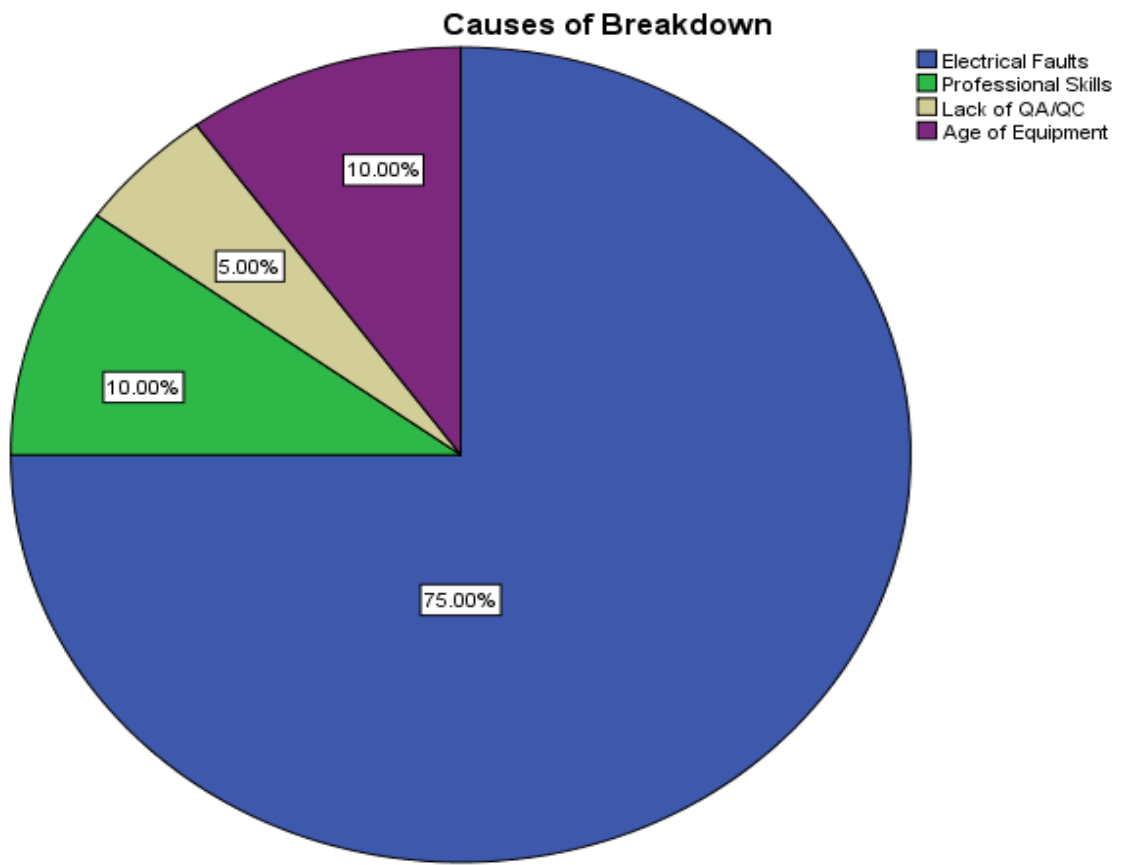

Fig 1:- Shows the Causes of Breakdown of Radiological Equipment

The pie chart above shows that the most common cause of equipment breakdown was due to electrical faults, $15(75 \%)$ and the least cause of breakdown was due to lack of quality assurance/quality control, 1(5\%).

\section{Frequency of Quality Control}

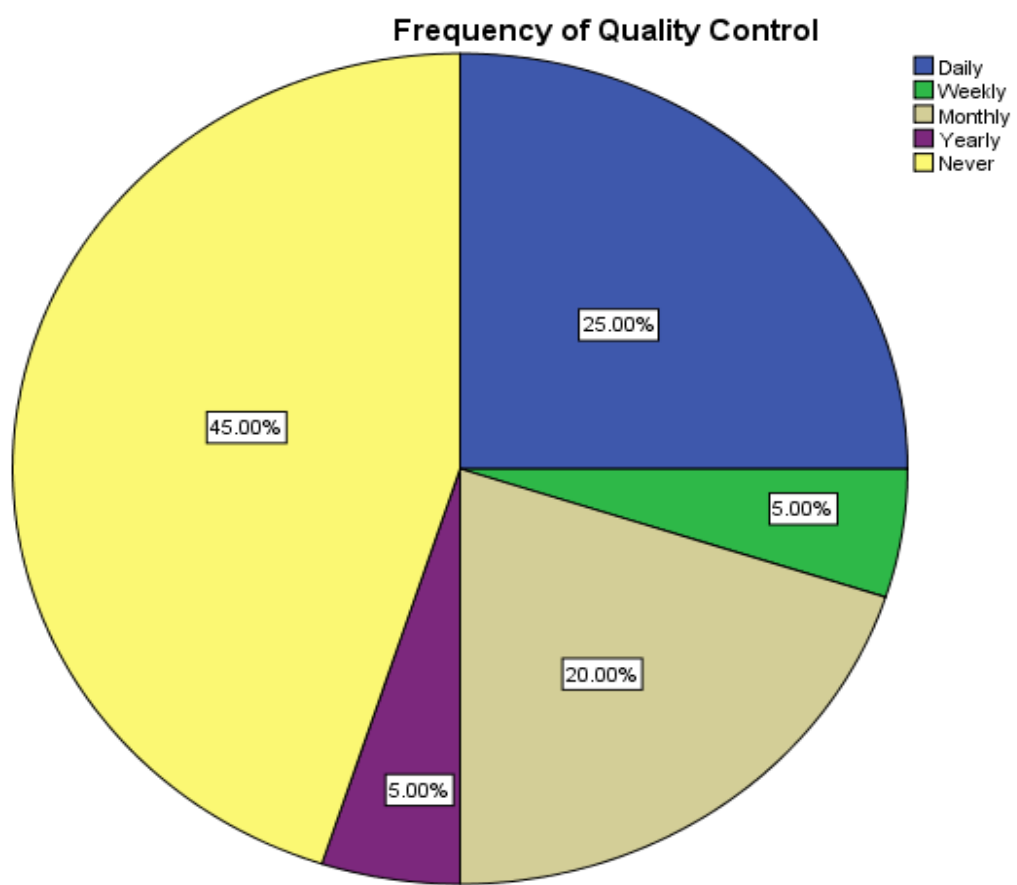

Fig 2:- Shows the Frequency of Quality Control Being Carried Out 
The pie chart above shows that the majority of the participant's never carryout quality control, $9(45 \%)$, while the minority carried out quality control weekly, 1(5\%) and yearly, 1(5\%)

Evaluating Measures Taken To Avoid Breakdown

\begin{tabular}{|c|c|c|}
\hline MEASURES TO AVOID BREAKDOWN & FREQUENCY & PERCENTAGES \\
\hline Cleaning of Equipment & $15 / 20$ & $75 \%$ \\
\hline Limitation of Exams & $3 / 20$ & $15 \%$ \\
\hline Electrical backup & $14 / 20$ & $70 \%$ \\
\hline Practice of Quality Control & $11 / 20$ & $55 \%$ \\
\hline Appropriate Parameters & $16 / 20$ & $80 \%$ \\
\hline Air Conditioning & $13 / 20$ & $65 \%$ \\
\hline
\end{tabular}

Table 2:- Shows the Measures Taken to Avoid Breakdown

The table shows that the most applied measure to avoid breakdown was use of appropriate parameters, $16 / 20(80 \%)$, while the least was limitation of exams, $3 / 20(15 \%)$.

\section{DISCUSSION, CONCLUSION AND RECOMMENDATION}

\section{A. Discussion}

Table 4.1 shows the demographic representation of participants. $75 \%$ were males and the $25 \%$ were females. The most represented age group was the 20-30yrs (50\%) and the least represented age group was the $42-52(5 \%)$. Majority of the participants had bachelor's degree $(65 \%)$ and few had master's degree $(10 \%)$. Most of the participants $(50 \%)$ had work experience ranging between $1-5 y r s$ and the least $(5 \%)$ had work experience ranging between 11-15 and >15yrs.

Based on the respondent opinion as demonstrated on figure 4.2 electrical faults was the major cause of equipment breakdown $(75 \%)$ because Cameroon is a poorly developed country with poor economy and poor power system so it is suffering from shortages in voltage which leads to insufficient and unreliable power supply to the equipment and secondly because of poor wiring of the building by the electrical engineer can damage the equipment, which is in line with the findings of Merlin et al 2015who discovered that the most common cause of equipment breakdown is power supply. The preceding cause of equipment breakdown was age of the equipment, $10 \%$ of participant's opinion was for this, because the equipment like $\mathrm{X}$-ray tube turns to wear out when used for long which is in line with the study of Boris et al, 2014who discovered that older equipment has a high risk of failures and breakdowns. There was lack of quality control $(5 \%)$ because the participants neglected to carryout quality control which puts the equipment at the risk of breakdown which is in line Okeji et al, 2012 who discovered that majority of the study participants did not carry out quality control program.

Information about the frequency of quality control(QC) was verified as shown on figure $4.3,45 \%$ of the study participantsdid not practice quality control because some of the institutions operate illegally and also because of the lack of qualified personnel to carry out the quality control, which is in linewith Oforiet al, 2013 who discovered that none of studied participants in the sampled hospitals carried out a quality control on their machines.it was observed that those who carried out QC did not do that on a regular bases because the quality control committee did not come on a regular bases which is still in line with ofOforiet al, 2013 who discovered that the radiation protection committee did not carry out QC test on the machines regularly.

Regarding measures to avoid the breakdown of equipment, based on respondent opinion, figure 4.4 shows that $80 \%$ of participants used appropriate parameters to avoid breakdown, this is done to prevent overheating of the devices and also depending on the size of their patients which is in line with Stephen et al, 2011 who discovered that there should be acceptable limits for the variation of parameters that is based on the personnel's opinion.it was observed that some participants practice cleaning $(75 \%)$ because cleaning will remove dust particles that might accumulate on the machine and it prevents cooling air from entering the machine thereby causing the machine to retain heat, optical interference,short and open circuits which in the long run will damage the machine.Despite the cleaning, some cleaning solutions such as alcohol and la Croix were used which corrodes metals, decolorize and cracks rubbers and certain plastics in the machine that leads in the reduction of the lifespan of the equipment which is not in line with GEhealthcare recommendations (2015) which recommends the use of chemicals with neutral $\mathrm{PH}$ for the cleaning of the device. it was observed that $70 \%$ of the study participants used electrical backup as a measure to avoid breakdown in case of low voltage, high voltage and power cuts. It is because of the repetitive power cuts in the health areas which is in line with the study of Hans, 2017 which wasdiscovered that in order to protect the equipment from damage by unexpected power disruption, there should be power backup supplies in the electrical system.15\% of the participants were of the opinion that to avoid the breakdown of equipment, there should be a limited number of exams taken per day because taking many exams such as lumbar spine which uses high exposure parameters will overwork the machine leading to its reduced life span which is in line withthe study of Boris et al, 2014 in which they discovered that the state of an equipment is affected 
by its utilisation and maintenance. $55 \%$ of the participants were of the opinion that the practice of quality control prevents equipment breakdown because routine check of the equipment will help detect when the equipment is not functioning properly which is in line with Ekpoet al2013who discovered that quality control will help prolong equipment life span and reduce potential risk due to equipment breakdown.

\section{B. Conclusion}

Based on the results obtained, it was observed that the major cause of equipment breakdown was due insufficient and unreliable power supply and lack of established quality control programs in the sampled hospitals. However it was therefore concluded that the measures used to avoid equipment breakdown by medical imaging personnel were; use of appropriate parameters, cleaning, electrical backup, practice of quality control, and limitation of exams.

\section{Recommendation}

The Cameroon National Commission of Radiation Protection (CNCRP) should investigate and make sure all imaging facilities are operating legally.

All health facilities should have an automated power backup electrical system for the imaging equipment.

Presentations should be organized in the radiological units to ensure proper knowledge on measures of avoiding equipment breakdown.

Qualified electrical engineers should be hired to wire the electrical system of the radiology units to avoid electrical faults which can affect the equipment.

\section{REFERENCES}

[1]. Anna Kowalika, Ewelina Konstanty (2010) Basic tests in mammography as a tool in quality Improvement. 1507-1367/\$ - see front matter c 2010 Greater Poland Cancer Centre, Poland. Published by Elsevier Urban \& Partner Sp. z.o.o. All rights reserved doi: 10.1016/j.rpor.2010.

[2]. American academy of family physicians Imaging personnel,

https://www.aafp.org/about/policies/all/imaging.htm 12019.

[3]. Boris Brkljačić, Mustafa Özmen, Peter Mildenberger, Elizabeth Schouman-Claeys, DenizAkata, Andrea Giovagnoni.Renewal of radiological equipment. Springerlink.com.2014

[4]. Certified veterinary assistant. Care of radiology equipment

[5]. Conference of radiation control program directors. Quality control recommendations for diagnostic radiography. Conference of radiation control program directors, inc.205 capital avenuefrankfort, kentucky 40601www.crcpd.org. 2001
[6]. Daniel R. de Camargo. Panoramic encompass user's manual. Model: HF100-Eagle. Classified C U L US document version:4 (2016)

[7]. Debashis Ganguly, Srabonti Chakraborty, Maricel Balitanas, and Tai-hoon Kim (2010) Medical Imaging: A Review.T.-h. Kim, A. Stoica, and R.-S. Chang (Eds.): SUComS 2010, CCIS 78, pp. 504516, 2010. (C) Springer-Verlag Berlin Heidelberg 2010

[8]. EK Ofori, WK Antwi, DN Scutt(2013) Current status of quality assurance in diagnostic imaging departments in Ghana.THE SOUTH AFRICAN RADIOGRAPHER volume 51 number 2 | NOVEMBER 2013.

[9]. EU Ekpo, NO Egbe, WEAzogor, SO Inyang, ER Upeh (2013) Challenges of radiological equipment management policies in some northern Nigerian hospitals.THE SOUTH AFRICA RADIOGRAPHER. MAY 2013 | volume 51 number 1

[10]. GE Healthcare. GE Transducer Cleaning and Disinfection Guidelines. 2015

[11]. George Allen. Implementing AORN Recommended Practices for Environmental Cleaning. 570 j AORN Journal__ May 2014 Vol 99 No 5

[12]. Guy Merlin Ngounou, Michael Gonin, Nicolas Gachet, Nicolas Crettenand (2015) Holistic Approach to Sufficient, Reliable, and Efficient Electricity Supply in Hospitals of Developing Countries - Cameroon Case Study.

[13]. Hansluppens. The importance of a UPS in medical imaging and diagnostics.https://blog.schneiderelectric.com/healthcare/2017/04/18/ups-medicalimaging-diagnostics

[14]. James A. Zagzebski, Nick Rupert, Ryan Dewall, Tomy Varghese. Routine ultrasound equipment tests for quality assurance (2010)

[15]. Korir G K,J S Wambani, I K Korir, M Tries, B Mulama.Quality management systems in radiology.S Afr J Rad 2013;17(3):84-88. DOI:10.7196/SAJR.886

[16]. Mammography quality assurance program management panel. Guidelines for quality control testing for digital CR DR Mammography. The Royal Australian and New Zealand college of Radiologist, version 4. (2018)

[17]. Mammootty IK. Quality assurance in dental radiography

https://www.slideshare.net>MammoottyIk

[18]. Marija Surić Mihić, Tomislav Meštrović, Ivica Prlić and Dunja Surić (2008) Importance of Quality Assurance Program Implementation in Conventional Diagnostic R adiology. Quality Assurance in Diagnostic Radiology, Coll. Antropol. 32 (2008) Suppl. 2: $181-184$

[19]. Medical radiology-Canadian, Winnipeg. Quality assurance and quality control in radiography.https://www.google.com/amp/s/rrcmrt. wordpress.com/2010/03/06/quality-assurance-andquality-control-in-radiography/amp/ 
[20]. MehrdadGholami, FatanehNemati, VahidKarami. The Evaluation of Conventional X-ray Exposure Parameters Including Tube Voltage and Exposure Time in Private and Government Hospitals of Lorestan Province, Iran. Iranian Journal of Medical Physics, Vol 12, No 2, Spring 2015, 8592

[21]. Monika mahajani. Diagnostic imaging. IMV congratulates philips north America for their outstanding service in imaging. https://imvinfo.com/press-room/imv-congratulatesservicetrak-awards-diagnostic-imaging-equipmentannounced-today 2018.

[22]. Okeji Mark C, Sobechukwu W. Onwuzu2, Joseph C. Eze, Ebere Ayogu. An Assessment of Equipment procurement and management policies in Radiology Centres in Nigeria.journal of Association of Radiographers of Nigeria, Vol. 26, (2012) 28 34

[23]. Pan American health organization. Mammography services quality assurance. Baseline standards for Latin America and the Caribbean. Universal copyright convention. (2016)

[24]. Peter J Lloyd. Quality assurance workbook for radiographers and radiological technologists. Diagnostic imaging and laboratory technology essential health technologies. Health technology and pharmaceutical World health organization. 2001 reprinted in 2004

[25]. Ramzee small, Quality assurance programme computed tomography (2017) https://www.slideshare.net>RamseySmall

[26]. Siemens. Somatom Instructions for Use - Drive. Print No. C2-047.621.03.02.02 | (C) Siemens Healthcare $\mathrm{GmbH}, 2016$ - 2016 for Use

[27]. Stephen Inkoom, Cyril Schandorf, Geoffrey EmiReynolds and John Justice Fletcher. Quality Assurance and Quality Control of Equipment in Diagnostic Radiology Practice-The Ghanaian Experience.https://www.researchgate.net/publicatio $\mathrm{n} / 221913318.2011$

[28]. Tim Szczykutowicz. Daily, weekly, and monthly QA testing on CT scanners scanning and analysis. https://www.radiology.wisc.edu/.../CT_Dailyweekly-CT-QA-Testing_Scanning And Analysis

[29]. Utah code. Radiologic Technologist, Radiologist Assistant and Radiology Practical Technician Licensing Act.https://le.utah.gov/xcode/Title58/.../C58-541800010118000101. 2011

[30]. WHO. Diagnostic imaging. http://www.who.int/diagnostic-imaging/en/.2019 